INTERNATIONAL JOURNAL OF

ATHLETIC THERAPY \& TRAINING

The Prolessional Journal of Certified Athletio Trainers and Athletio Therapists

\title{
Novel isokinetic dynamometry of the thigh musculature during anterior cruciate ligament rehabilitation in professional soccer: an explorative case study
}

\begin{tabular}{|r|l|}
\hline Journal: & International Journal of Athletic Therapy \& Training \\
\hline Manuscript ID & IJATT.2017-0081.R3 \\
\hline Manuscript Type: & Clinical CASE Report \\
\hline Keywords: & knee injury, strength profiling, soccer, hamstrings, quadriceps \\
\hline Specialty Areas: & $\begin{array}{l}\text { Isokinetic < Functional progressions < Rehabilitation < Examination, } \\
\text { Treatment, and Rehabilitation }\end{array}$ \\
\hline \multicolumn{2}{|l}{} \\
\hline
\end{tabular}

SCHOLARONE ${ }^{m}$

Manuscripts 
1 Novel isokinetic dynamometry of the thigh musculature during anterior cruciate

2 ligament rehabilitation in professional soccer: an explorative case study

3

4 Abstract

5 The purpose was to assess the isokinetic strength adaptations of eccentric knee flexors (eccKF)

6 and concentric knee extensors (conKE) in a professional male soccer player during anterior

7 cruciate ligament (ACL) rehabilitation. Progress was monitored relative to a non-injured

8 control group. Isokinetic strength assessments were initiated 18 weeks post ACL reconstruction

9 and comprised assessments at eight angular velocities between 60 and $270^{\circ} \cdot \mathrm{s}^{-1}$. The

10 assessments ceased at the point where the player was cleared for return to play 6 months after

11 reconstructive surgery by his club. The results identified that conKE peak torque of the

12 treatment limb and eccKF peak torque of both lower limbs demonstrated meaningful changes.

13 In addition, the eccKF angle of peak torque also demonstrated meaningful change that occurred

14 at increased knee extension. The inclusion of additional angular velocities and angle specific

15 measures provide new insight into rehabilitation and return to play.

16 Key points

17 - Angle specific isokinetic strength assessments should be conducted at varying angular 18 velocities at the point of return to play.

19 - Isokinetic assessments should consider an angle specific function strength ratio at the 20 point of return to play.

21 - The slope of the force-velocity curve is changeable through rehabilitation

22 Key words

23 Knee injury, strength profiling, soccer, hamstring, quadriceps 


\section{Introduction}

2 A study in professional male soccer reported that only $65 \%$ of players who sustain an anterior

3 cruciate ligament (ACL) injury return to previous competitive levels three years after injury. ${ }^{1}$

4 Secondary ACL injuries are also common amongst professional soccer players, attributed to

5 strength impairments of knee flexor (KF) and extensor (KE) musculature at the point of return

6 to play. ${ }^{2,3}$ Given the functional role in stabilising the knee, ${ }^{4}$ adaptation of the $\mathrm{KF}$ and $\mathrm{KE}$

7 musculature during rehabilitation is of primary importance.

8 Isokinetic assessments of concentric $\mathrm{KF}$ and $\mathrm{KE}$ strength are used to identify rehabilitation

9 responses and bilateral asymmetry at the point of return to play. ${ }^{5,6}$ However, failure to consider

10 the functional eccKF:conKE ratio $^{7}$ and slow testing velocities in relation to injury mechanism

11 limits functional interpretation. Specifically, ACL injury risk is associated with lower

12 functional eccKF:conKE ratio's that indicate higher $\mathrm{KE}$ strength relative to the KF

13 musculature, thereby increasing ACL strain. ${ }^{8}$ As functional movements associated with ACL

14 injury ${ }^{9,10}$ exhibit increased knee angular velocities ${ }^{11}$, isokinetic strength assessments should

15 therefore be characterised by $\mathrm{KF}$ and $\mathrm{KE}$ at similar testing velocities. Furthermore, whilst

16 isokinetic assessment of $\mathrm{KF}$ and $\mathrm{KE}$ strength is common within professional soccer, ${ }^{12}$ the sole

17 use of functional eccKF:conKE ratio fails to consider that KF and KE peak torques (PT) occur

18 at different knee joint angles. ${ }^{13}$ When considering the injury mechanisms associated with ACL

19 injury, ${ }^{14,15}$ angle specific strength measures should be considered at relevant knee extension

20 angles and angular velocities.

21 A common return to play criteria in professional soccer assesses bilateral strength asymmetry

22 of both the injured and non-injured lower limbs, where values less than $10 \%$ are considered

23 acceptable. ${ }^{8}$ However, following a prolonged rehabilitation period, the detrained and atrophied

24 non-injured limb may not represent a suitable control. Therefore, a healthy control group may 
1 be used to help identify whether strength deficits exist in injured populations. ${ }^{6}$ Return to play

2 guidelines also suggest KE strength asymmetries greater than $10 \%$ and returning to play before

39 months postoperative surgery are significant predictors of ACL re-injury, ${ }^{8}$ thus reiterating

4 the importance of sufficient rehabilitation. The primary aim of this study was to observe

5 changes in a professional soccer player's isokinetic bilateral strength at varying angular

6 velocities during late stage rehabilitation from ACL reconstructive surgery. A second aim of

7 the study was to compare these data to that of a healthy control group. The final aim of this

8 study was to consider both angle specific and non-angle specific strength ratios at the point of

9 return to play.

\section{Case Presentation}

\section{Patient}

12 The case was a 26 year-old professional male soccer player (height: $184.50 \mathrm{~cm}$; mass: 84.50

$13 \mathrm{~kg}$ ) from the English Football League Division Two. The injury occurred in January 2016

14 during a contact situation where the case collided with an opponent attempting a tackle, injuring

15 the dominant right lower limb (defined as the preferred kicking limb). ${ }^{13}$ The present injury

16 occurred during the first 15 minutes of a match. The ACL injury was confirmed by a magnetic

17 resonance imaging scan, revealing a grade III tear. Surgical reconstruction of the right ACL

18 was performed via patella tendon graft 7 weeks after injury. An injury also occurred to the

19 medial collateral ligament (MCL) with a grade III tear to the right lower limb 5 months prior

20 to the present injury. The case has also previously injured their left ACL $\sim 8$ years prior to the

21 present injury. A hamstring tendon was used to reconstruct their left ACL.

\section{Intervention}

23 During the first visit to the laboratory, case and club consent were obtained for the assessment 24 of isokinetic (System 4, Biodex Medical Systems, New York, USA) eccentric KF (eccKF) and 25 concentric KE (conKE) strength from 18 weeks post ACL reconstruction to return to play. To 
1 replicate the club training times ${ }^{16}$ testing was conducted between 1000-1200 hours over five

2 trials, comprising one familiarisation trial and four isokinetic strength assessments interspersed

3 by two weeks. Before each trial, a standardised 5 minute warm-up on a stationary cycle

4 ergometer was completed (Monark, 824E, Sweden) at 60W.

5

6 Bilateral isokinetic strength of eccKF and conKE were completed at eight angular velocities 7 completed in the order of 150, 180, 120, 210, 90, 240, 60 and $270^{\circ} \cdot \mathrm{s}^{-1} \cdot{ }^{17}$ At each angular 8 velocity, the case was instructed to exert maximal effort for 3 repetitions, with no performance 9 feedback. ${ }^{12,18}$ The dynamometer setup was adjusted specifically for the participant in line with 10 the manufacturer's guidelines, with the cuff of the lever arm secured around the ankle proximal 11 to the malleoli. The case was secured in a seated position with the hip positioned at approximately $90^{\circ}$. Restraints were applied proximal to the knee joint across the thigh, waist and chest. The repetition eliciting the highest PT was further analysed to quantify the corresponding angle of peak torque (APT) and the slope of the force-velocity curve $(M)^{19}$ :

$$
M=(\text { Torque }[\mathrm{Y} 2-\mathrm{Y} 1]) /(\text { Angular Velocity }[\mathrm{X} 2-\mathrm{X} 1])
$$

The $M$ value quantified the slope of the force-velocity curve by each PT value for eccKF and conKE contractions across angular velocities (i.e. Y2 and X2 referred to PT data at $270^{\circ} \cdot \mathrm{s}^{-1}$, whereas Y1 and X1 referred to PT data recorded at $\left.60^{\circ} \cdot \mathrm{s}^{-1}\right)$. The $M$ value was used to describe the slope of the force-velocity curve for the respective musculature. Strength ratios were defined as the eccKF:conKE ratio ${ }^{7}$ derived from the peak eccKF and conKE values. When considering that ACL injuries have previously been reported to occur when the shank is in a more extended position, ${ }^{9,14}$ the strength ratios (angle specific eccKF:conKE ratio) were also 23 calculated from torque data recorded at the angle of maximal knee extension $\left(40^{\circ}\right.$ of knee 24 flexion) common to all testing velocities. A rehabilitation response was determined by 
1 comparing the data recorded for both the treatment and uninvolved limbs across weeks of the

2 rehabilitation. The within-subject standard deviation for all four assessments were used to

3 calculate standard error of measurement (SEM), ${ }^{20}$ with bilateral changes greater than the SEM

4 being regarded as meaningful. ${ }^{21}$ To determine a treatment effect, the data recorded from the

5 initial assessment (week 18) was compared to that at the point where the club decided the player

6 was returning to play (week 24). Where appropriate, both the rehabilitation and treatment

7 effects were quantified using both absolute and relative differences.

8 In addition to the aforementioned analyses, the final isokinetic strength assessment (week 24)

9 was compared to a control group of 26 male soccer players (age $26.19 \pm 4.65$ years; height

$10181.65 \pm 5.71 \mathrm{~cm}$; mass $82.19 \pm 9.01 \mathrm{~kg}$ ) who were injury free $\geq 6$ months, prior to data

11 collection. All players within the control group had no previous history of surgery or trauma to

12 the knee. The control group were recruited from the same team to control for differences in

13 training. The control group data comprised average PT, APT, and the eccKF:conKE ratio data

14 recorded from isokinetic bilateral strength assessments of the eccKF and conKE musculature

15 at angular velocities of 180,270 and $60^{\circ} \cdot \mathrm{s}^{-1}$.

\section{Comparative outcomes}

17 Tables 1 and 2 summarise the biweekly rehabilitation responses for the uninvolved and 18 treatment limbs during the assessment period. At the initial assessment (Week 18), bilateral 19 differences in eccKF PT were greater than the SEM at only $150-180^{\circ} \cdot \mathrm{s}^{-1}$ (Table 1 ). By Week 24 the bilateral difference in PT was smaller than the SEM at all testing velocities (Table 1). In contrast, the initial assessment at Week 18 revealed that bilateral differences in conKE PT were greater than the SEM at all testing velocities (Table 2). This bilateral difference was maintained throughout the rehabilitation period, with the bilateral difference less than the SEM at Week 24 only at the highest testing velocity of $270^{\circ} \cdot \mathrm{s}^{-1}$. 
[Table 1 near here]

[Table 2 near here]

3 Table 3 summarises the overall treatment effect during the rehabilitation period. Meaningful

4 changes (greater than SEM) were achieved in eccKF PT at all velocities for the treatment limb,

5 and all velocities except $150-180^{\circ} \cdot \mathrm{s}^{-1}$ in the uninvolved limb. The treatment limb also showed

6 a meaningful change in eccKF APT at all velocities except $210^{\circ} \cdot \mathrm{s}^{-1}$ and $270^{\circ} \cdot \mathrm{s}^{-1}$. Meaningful

7 changes in eccKF APT in the uninvolved limb were observed at $90^{\circ} \cdot \mathrm{s}^{-1}$ and $210-270^{\circ} \cdot \mathrm{s}^{-1}$. In

8 conKE PT, meaningful changes were evident at all velocities in the treatment limb, whilst no

9 meaningful changes were observed in the uninvolved limb. The APT data recorded for the

10 treatment limb's conKE data also identified a meaningful effect at all angular velocities except

$11 \quad 120^{\circ} \cdot \mathrm{s}^{-1}$ and $240^{\circ} \cdot \mathrm{s}^{-1}$. The uninvolved limb showed a meaningful change in conKE APT only at $60^{\circ} \cdot \mathrm{s}^{-1}$ and $180^{\circ} \cdot \mathrm{s}^{-1}$.

14 In relation to the additional analyses, it was also identified that the eccKF and conKE slopes 15 (as determined by the $M$ values) decreased and increased respectively during the rehabilitation 16 period. Table 4 identifies differences between the eccKF:conKE ratio and angle specific 17 eccKF:conKE ratio data at the point of return to play, with increased angle specific eccKF:conKE ratios ( $40^{\circ}$ knee flexion) being identified for both the uninvolved and treatment 19 limbs.

20 The control group PT values (normalised to body mass) are illustrated in Figure 1. At return to 21 play, conKE PT data recorded for the uninvolved limb was within $10 \%$ of that elicited from 22 the control group. The conKE PT data recorded for the treatment limb was lower when 23 compared to the mean data, but were within the range of the control group (Figure 1). As 
1 identified in Figure 1, the eccKF PT data recorded across both of the case's limbs were similar

2 to that of the control group. Due to the observed strength deficits in the conKE musculature,

3 the eccKF:conKE ratio for the treatment limb were greater than both the uninvolved limb and

4 the control group (Figure 2).

5

6

7

\section{Discussion}

9 The aims of this study were threefold. Firstly, to quantify the strength characteristics of the eccKF and conKE musculature across a range of angular velocities during late stage ACL

11 rehabilitation in a professional soccer player. Secondly, to compare these data to that of a 12 healthy control group. Thirdly, to consider both angle specific and non-angle specific strength 13 ratios at the point of return to play.

14 Typically practitioners identify strength asymmetries between injured and non-injured limbs, 15 forming part of return to play criteria. ${ }^{8}$ However, the use of bilateral asymmetries are not 16 entirely appropriate as detraining effects can also occur in a non-injured limb. ${ }^{5}$ In relation to 17 the first aim, at week 18 large bilateral differences were observed across all angular velocities for both the eccKF and conKE musculature. The bilateral differences did fluctuate throughout the rehabilitation period; however, lower bilateral differences were consistently identified for the eccKF data, with differences lower than the SEM identified at the final assessment. The conKE data however elicited a response whereby the bilateral differences were consistently greater than those associated with the eccKF data, and at the final assessment, the observed differences were greater than the SEM. When considering the role of the KE musculature in 
1 relation to knee stability, ${ }^{14}$ these data therefore suggest that at the point of return to play, the

2 player may be at an increased risk of re-injury. ${ }^{2,3,8}$ Consequently, practitioners should monitor

3 and focus on restoring conKE strength after an ACL injury. Especially when considering that

4 the current rehabilitation programme appears to be insufficient to develop the PT of the conKE

5 musculature. It should however be acknowledged that for the current case, the club deemed

6 the player to be ready to return to play even with the knowledge of these data.

7 When considering the previous criticisms of bilateral comparisons to inform return to play

8 decisions, ${ }^{5}$ an alternative method is to compare the data recorded from the injured player to that

9 of a non-injured control group. This was considered in relation to the second aim of the study, with the conKE and eccKF PT data recorded for both limbs being within the range of the control group. These data therefore suggest that relative to a non-injured population, the case possessed sufficient thigh muscular strength characteristics, thus suggesting they may be appropriately adapted to return to play. The current data did however identify that the eccKF: conKE ratio was considerably larger for the treatment limb when compared to both the uninvolved limb and the control group's data. This response is a result of the impaired conKE musculature identified at the point of return to play, and further advocates the use of a number 17 of strength characteristics to determine a player's readiness to return to play. Furthermore, when considering the aforementioned bilateral differences identified across the rehabilitation period, these data also support the use of a number of methods to inform return to play decisions.

The rehabilitation responses for the treatment limb identified large changes in PT for both the eccKF and conKE musculature at all angular velocities, with direct influence on the force velocity slopes. Specifically, improvements were identified across all velocities; however,

24 these improvements did elicit a trend for a reduced absolute magnitude change as a main effect 25 for increased velocity. As such, although the $M$ value increased for the conKE data of the 
1 treatment limb, the observed change in the slope was small due to the somewhat similar 2 upwards shift in torque identified for all testing velocities. The slope of the eccKF PT recorded 3 across the angular velocities decreased during the rehabilitation period for both lower limbs. 4 As such, the eccKF slope at the point of return to play better resembled that previously observed 5 in non-injured players, whereby more consistent PT is observed across all testing velocities. ${ }^{22}$

6 These novel findings suggest that the force-velocity slope is modifiable through rehabilitation 7 and training, with this response being relative to both the muscle group and contraction type. 8 These data therefore have potential implication for exercise prescription and training adaptation 9 monitoring.

10 Although the changes in conKE APT were variable in both lower limbs during the assessment 11 period, APT of eccKF demonstrated large changes with greater force production at increased 12 knee extension angles. The observed shift of eccKF PT towards increased knee extension suggests that the KF musculature may better conditioned to stabilise the knee joint at those angles associated with ACL injury. ${ }^{14}$ These data therefore identify the importance of including a number of isokinetic metrics when analysing training induced changes in strength characteristics.

17 The calculation of the eccKF:conKE ratio is typically performed using peak torque data without consideration that eccKF and conKE peak at different knee joint angles. ${ }^{7}$ These ratios therefore negate consideration of angle matched torques, and also the consideration of ipsilateral imbalances in an extended position, where ACL injuries have previously been identified to 21 most likely occur. ${ }^{14}$ Previous studies have therefore attempted to assess angle specific eccKF:conKE ratios in soccer players, with a consensus that these players typically possess increased eccKF torque towards more extended knee angles when compared to the conKE 24 musculature. This is supported by the current data, whereby the angle specific eccKF:conKE 25 ratio values were notably higher in the treatment limb, as a result of impaired conKE torque at 
1 increased knee extension angles across all testing velocities. This response was not however

2 observed to the same magnitude for the non-angle specific eccKF:conKE strength ratio. These

3 data therefore reiterate the importance of ensuring the conKE musculature possesses sufficient

4 strength at more extended knee angles, and raises questions about the use of non-angle specific

5 strength ratios as a means of determining return to play.

\section{Clinical Bottom Line}

7 This present study provides insight into how the strength characteristics of the eccKF and

8 conKE musculature adapted to late stage ACL rehabilitation in a professional male soccer

9 player. It was identified that at the point of return to play, bilateral differences were identified

10 for the conKE data recorded from the case's treatment limb, with potential implications for an

11 increased risk of injury. ${ }^{2,3,8}$ In contrast to this, irrespective of limb, the conKE and eccKF PT

12 data was identified to be within the range associated with a non-injured control group.

13 Observed changes were also identified for the eccKF APT data as a result of the rehabilitation

14 process, thus suggesting the ability to modify this metric through training. The observed

15 response was for eccKF PT to occur in a more extended knee position, thus potentially offering

16 a protective mechanism to future ACL injury risk. An additional novel consideration of the

17 current study was to quantify the force-velocity slope as a method of assessing the

18 rehabilitation response. This method could be considered for future work to provide a single

19 number to quantify the shift in this slope, thus providing an understanding of the velocity

20 dependent training response. The final consideration of the current study was to compare both

21 angle specific and non-angle specific strength ratios. The current data identified that strength

22 ratios towards a more extended knee angle identified large ipsilateral strength deficits that were

23 not of the same magnitude with the non-angle specific ratios. These data therefore support the

24 use of ipsilateral, bilateral, and between group comparisons and the use of a number of strength

25 metrics to better inform return to play decision-making. 


\section{References}

2 1. Walden, M., Hagglund, M., Magnusson, H. and Ekstrand, J. ACL injuries in men's

3 professional football: a 15-year prospective study on time trends and return-to-play rates reveals only $65 \%$ of players still play at the top level 3 years after ACL rupture. Br J Sports Med. 2016; 50(12):744-750.

2. Schmitt, L.C., Paterno, M.V., Ford, K.R., Myer, G.D. and Hewett, T.E. Strength Asymmetry and Landing Mechanics at Return to Sport after Anterior Cruciate Ligament Reconstruction. Med Sci Sports Exerc. 2015; 47(7): 1426-1434.

3. Kyritsis, P., Bahr, R., Landreau, P., Miladi, R. and Witvrouw, E. Likelihood of ACL graft rupture: not meeting six clinical discharge criteria before return to sport is associated with a four times greater risk of rupture. Br J Sports Med. 2016; 50.15: 946-951.

4. Kellis, E. Arabatzi, F. and Papadopoulos C. Muscle co-activation around the knee in drop jumping using the co-contraction index. J Electromyogr Kinesiol. 2003; 12(3):229-238.

5. Thomas, A.C., Villwock, M., Wojtys, E.M. and Palmieri-smith, R. Lower Extremity Muscle Strength After Anterior Cruciate Ligament Injury and Reconstruction. J Athl Train.

6. Czaplicki, A., Jarocka, M. and Walawski, J. Isokinetic Identification of Knee Joint Torques before and after Anterior Cruciate Ligament Reconstruction. PLoS One. 2015; 10(12):1-

7. Aagaard, P., Simonsen, E.B., Magnusson, S.P., Larsson, B. and Dyhre-poulsen, P. A new concept for isokinetic hamstring: quadriceps muscle strength ratio. Am J Sports Med.1998; 26(2): 231-237.

8. Grindem, H., Snyder-Mackler, L., Moksnes, H., Engebretsen, L. and Risberg, M.A. Simple decision rules can reduce reinjury risk by $84 \%$ after ACL reconstruction: the Delaware- 
1 9. Olsen, O.E., Myklebust, G., Engebretsen, L. and Bahr, R. Injury Mechanisms for Anterior

2 Cruciate Ligament injuries in Team Handball: A Systematic Video Analysis. J. Orthop. $3 \quad$ Sports Phys. Ther. 2005; 32(4): 1002-1012

4 10. Pappas, E., Hagins, M., Sheikhzadeh, A., Nordin, M., Rose D. Biomechanical differences 5 between unilateral and bilateral landings from a jump: Gender differences. Clin J Sport $6 \quad$ Med. 2007; 17(4):263-268.

7 11. Nedergaard, N., J., Kersting, U., Lake, M. Using accelerometry to quantify deceleration 8 during a high-intensity soccer turning manoeuvre. J Sports Sci. 2014; 32(20):1897-1905.

9 12. Croisier, J., Ganteaume, S., Binet, J., Genty, M. and Ferret, J. Strength imbalances and prevention of hamstring injury in professional soccer players: a prospective study. Am J Sports Med.2008 36(8):1469-1475.

13. Eustace, S.J., Page, R.M. and Greig, M. Contemporary approaches to isokinetic strength assessments in professional football players. Science and Medicine in Football. 2017;1(3) 251-257.

14. Boden, B., P., Dean, G., S. Mechanisms of anterior cruciate ligament injury. Orthopedics. 2000; 23(6):578-586.

15. Hsiao, S., Chou, P., Hsu, H. and Lue, Y. Changes of muscle mechanics associated with anterior cruciate ligament deficiency and reconstruction. J Strength Cond Res. 2014; 28(2):390-400.

16. Rae, D., Stephenson, K. and Roden, L. Factors to consider when assessing diurnal variation in sports performance: the influence of chronotype and habitual training time-of-day. $J$ Appl Physiol. 2015; 115(6):1339-1349.

17. Greig, M. The influence of soccer-specific fatigue on peak isokinetic torque production of the knee flexors and extensors. Am J Sports Med. 2008; 36(7):1403-1409. 
1 18. Campenella, B., Mattacola, C.G. and Kimura, I.F. Effect of visual feedback and verbal 2 encouragement on concentric quadriceps and hamstrings peak torque of males and 3 females. Isokinet Exerc Sci. 2000; 8(1):1.

4 19. Rock, N., M. Math for Everyone: Algebra I. Team Rock Press; 2007.

5 20. Bland, J., M., and Altman D., G. Measurement Error. BMJ. 1996; 313:744-753.

6 21. Mchorney, C.A. and Tarlov, A.R. Individual-patient monitoring in clinical practice: are 7 available health status surveys adequate? Quality Of Life Research: Qual Life $8 \quad$ Res. 1995; 4(4):293-307.

9 22. Westing S.,H., Seger J., Karlson, E., Ekblom, K. Eccentric and concentric torque-velocity 10 characteristics of the quadriceps femoris in man. Eur J Appl Physiol. 1988; 58(1):100-104. 11 23. Small, K., McNaughton L., Greig M., Lovell R. The Effects of Multidirectional Soccer12 Specific Fatigue on Markers of Hamstring Injury Risk. J Sci Med Sport. 2010; 13 (1):120125. 


\section{$1 \quad$ List of Tables}

2 Table 1: The rehabilitation responses of the PT, APT, and $M$ data recorded for the eccKF

3 musculature of the uninvolved and treatment limbs. The bilateral differences for the biweekly

4 assessments are also presented, with a positive value representing a higher value for the

5 treatment limb.

6 Table 2: The rehabilitation responses of the PT, APT, and $M$ data recorded for the conKE

7 musculature of the uninvolved and treatment limbs. The bilateral differences for the biweekly

8 assessments are also presented, with a positive value representing a higher value for the 9 treatment limb.

10 Table 3: The treatment effect for the PT and APT data recorded for the eccKF and conKE

11 musculature of the uninvolved and treatment limbs. A negative PT value indicates a reduction

12 during the 6 week period. A negative APT value indicates a change towards more extended

13 knee angle.

14 Table 4. Angle specific and non-angle specific strength ratios recorded across all angular

15 velocities at the point of return to play 


\section{Figure Legends}

2 Figure 1. Isokinetic peak torque (normalized to body mass) of conKE (A) and eccKF (B) 3 musculature recorded at 60,180 and $270^{\circ} \cdot \mathrm{s}^{-1}$ for both the uninvolved limb (- •-) and the

4 treatment limb ( $\longrightarrow$ ) of the case, and also for the control group $(-)$ ) at the point of return 5 to play.

6 Figure 2. The eccKF:conKE strength ratio recorded at 60,180 and $270^{\circ} \cdot \mathrm{s}^{-1}$ for uninvolved limb $7 \quad(-\bullet-)$, treatment limb (־) of present case and control group $(-\bullet)$ at return to play. 
Table 1: The rehabilitation responses of the PT, APT, and $M$ data recorded for the eccKF musculature of the uninvolved and treatment limbs. The bilateral differences for the biweekly assessments are also presented, with a positive value representing a higher value for the treatment limb.

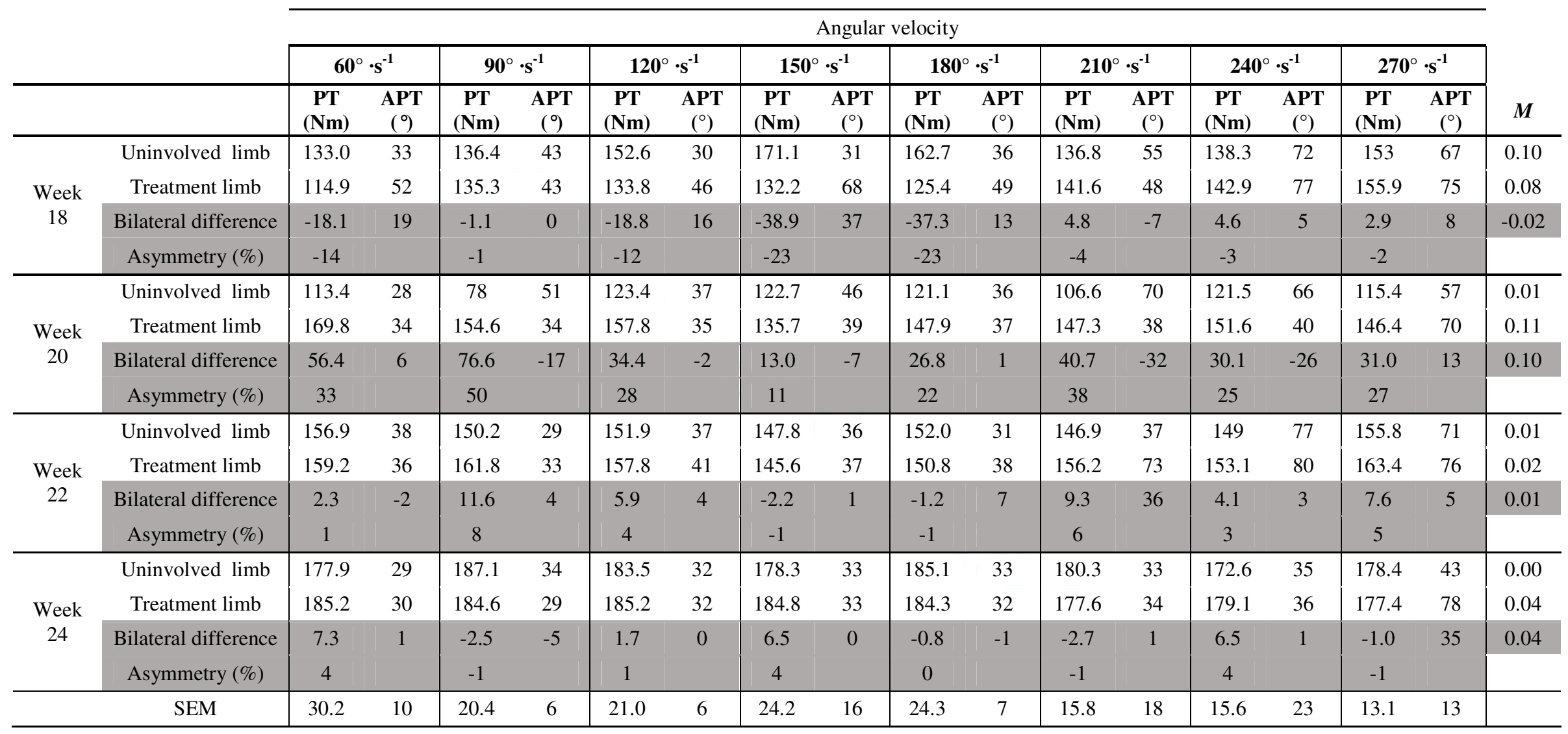


Table 2: The rehabilitation responses of the PT, APT, and $M$ data recorded for the conKE musculature of the uninvolved and treatment limbs. The bilateral differences for the biweekly assessments are also presented, with a positive value representing a higher value for the treatment limb.

\begin{tabular}{|c|c|c|c|c|c|c|c|c|c|c|c|c|c|c|c|c|c|c|}
\hline & & \multicolumn{16}{|c|}{ Angular velocity } & \multirow[b]{3}{*}{$M$} \\
\hline & & \multicolumn{2}{|c|}{$60^{\circ} \cdot s^{-1}$} & \multicolumn{2}{|c|}{$90^{\circ} \cdot \mathrm{s}^{-1}$} & \multicolumn{2}{|c|}{$120^{\circ} \cdot \mathrm{s}^{-1}$} & \multicolumn{2}{|c|}{$150^{\circ} \cdot \mathrm{s}^{-1}$} & \multicolumn{2}{|c|}{$180^{\circ} \cdot \mathrm{s}^{-1}$} & \multicolumn{2}{|c|}{$210^{\circ} \cdot \mathrm{s}^{-1}$} & \multicolumn{2}{|c|}{$240^{\circ} \cdot \mathrm{s}^{-1}$} & \multicolumn{2}{|c|}{$270^{\circ} \cdot \mathrm{s}^{-1}$} & \\
\hline & & $\begin{array}{c}\text { PT } \\
(\mathbf{N m})\end{array}$ & $\begin{array}{c}\text { APT } \\
\left({ }^{\circ}\right) \\
\end{array}$ & $\begin{array}{c}\text { PT } \\
(\mathbf{N m})\end{array}$ & $\begin{array}{c}\text { APT } \\
\left({ }^{\circ}\right)\end{array}$ & $\begin{array}{c}\text { PT } \\
(\mathbf{N m})\end{array}$ & $\begin{array}{c}\text { APT } \\
\left({ }^{\circ}\right)\end{array}$ & $\begin{array}{c}\text { PT } \\
(\mathbf{N m})\end{array}$ & $\begin{array}{c}\text { APT } \\
\left({ }^{\circ}\right)\end{array}$ & $\begin{array}{c}\text { PT } \\
(\mathbf{N m}) \\
\end{array}$ & $\begin{array}{c}\text { APT } \\
\left({ }^{\circ}\right)\end{array}$ & $\begin{array}{c}\begin{array}{c}\text { PT } \\
(\mathbf{N m})\end{array} \\
\end{array}$ & $\begin{array}{c}\text { APT } \\
\left({ }^{\circ}\right)\end{array}$ & $\begin{array}{c}\begin{array}{c}\text { PT } \\
(\mathbf{N m})\end{array} \\
\end{array}$ & $\begin{array}{c}\text { APT } \\
\left({ }^{\circ}\right)\end{array}$ & $\begin{array}{c}\begin{array}{c}\text { PT } \\
(\mathbf{N m})\end{array} \\
\end{array}$ & $\begin{array}{c}\text { APT } \\
\left({ }^{\circ}\right)\end{array}$ & \\
\hline \multirow{4}{*}{$\begin{array}{c}\text { Week } \\
18\end{array}$} & Uninvolved limb & 230.2 & 81 & 211.1 & 72 & 197.3 & 80 & 176.7 & 77 & 184.0 & 73 & 177.1 & 70 & 160.3 & 67 & 140.8 & 62 & 0.43 \\
\hline & Treatment limb & 132.2 & 80 & 129.8 & 70 & 125.2 & 78 & 108.1 & 72 & 112.1 & 72 & 100.9 & 66 & 102.5 & 67 & 91.9 & 67 & 0.19 \\
\hline & Bilateral difference & -98.0 & -1 & -81.3 & -2 & -72.1 & -2 & -68.6 & -5 & -71.9 & -1 & -76.2 & -4 & -57.8 & 0 & -48.9 & 5 & -0.24 \\
\hline & Asymmetry (\%) & -43 & & -39 & & -37 & & -39 & & -39 & & -43 & & -36 & & -35 & & \\
\hline \multirow{4}{*}{$\begin{array}{c}\text { Week } \\
20\end{array}$} & Uninvolved limb & 200.6 & 74 & 176.1 & 78 & 175.9 & 76 & 162.9 & 73 & 167.2 & 69 & 154.7 & 65 & 134.5 & 61 & 127.7 & 58 & 0.35 \\
\hline & Treatment limb & 156.8 & 82 & 157.7 & 75 & 146.2 & 68 & 125.0 & 78 & 133.0 & 73 & 132.5 & 72 & 124.6 & 73 & 118.5 & 67 & 0.18 \\
\hline & Bilateral difference & -43.8 & 8 & -18.4 & -3 & -29.7 & -8 & -37.9 & 5 & -34.2 & 4 & -22.2 & 7 & -9.9 & 12 & -9.2 & 9 & -0.17 \\
\hline & Asymmetry (\%) & -22 & & -10 & & -17 & & -23 & & -20 & & -14 & & -7 & & -7 & & \\
\hline \multirow{4}{*}{$\begin{array}{c}\text { Week } \\
22\end{array}$} & Uninvolved limb & 213.0 & 80 & 193.4 & 70 & 183.5 & 75 & 189.4 & 72 & 182.2 & 68 & 170.4 & 68 & 153.4 & 64 & 161.8 & 66 & 0.24 \\
\hline & Treatment limb & 163.1 & 83 & 150.5 & 75 & 139.7 & 69 & 124.1 & 78 & 122.9 & 73 & 123.3 & 73 & 118.1 & 63 & 107.5 & 64 & 0.27 \\
\hline & Bilateral difference & -49.9 & 3 & -42.9 & 5 & -43.8 & -6 & -65.3 & 6 & -59.3 & 5 & -47.1 & 5 & -35.3 & -1 & -54.3 & -2 & 0.03 \\
\hline & Asymmetry (\%) & -23 & & -22 & & -24 & & -34 & & -33 & & -28 & & -23 & & -34 & & \\
\hline \multirow{5}{*}{$\begin{array}{c}\text { Week } \\
24\end{array}$} & Uninvolved limb & 222.2 & 71 & 206.8 & 68 & 204.2 & 74 & 182.4 & 76 & 184.6 & 69 & 181.2 & 66 & 177.8 & 64 & 157.6 & 60 & 0.31 \\
\hline & Treatment limb & 185.6 & 83 & 178.0 & 77 & 161.0 & 82 & 163.4 & 75 & 156.8 & 74 & 149.4 & 75 & 150.1 & 67 & 138.3 & 83 & 0.23 \\
\hline & Bilateral difference & -36.6 & 12 & -28.8 & 9 & -43.2 & 8 & -19.0 & -1 & -27.8 & 5 & -31.8 & 9 & -27.7 & 3 & -19.3 & 23 & -0.08 \\
\hline & Asymmetry (\%) & -16 & & -14 & & -21 & & -10 & & -15 & & -18 & & -16 & & -12 & & \\
\hline & SEM & 22.0 & 1 & 19.9 & 3 & 23.5 & 7 & 14.9 & 3 & 8.5 & 1 & 20.2 & 4 & 19.8 & 4 & 19.5 & 3 & \\
\hline
\end{tabular}


Table 3: The treatment effect for the PT and APT data recorded for the eccKF and conKE musculature of the uninvolved and treatment limbs. A negative PT value indicates a reduction during the 6 week period. A negative APT value indicates a change towards more extended knee angle.

\begin{tabular}{|c|c|c|c|c|c|c|c|c|c|c|c|c|c|c|c|c|}
\hline \multirow{3}{*}{ eccKF } & \multicolumn{16}{|c|}{ Angular velocity } \\
\hline & \multicolumn{2}{|c|}{$60^{\circ} \cdot s^{-1}$} & \multicolumn{2}{|c|}{$90^{\circ} \cdot \mathrm{s}^{-1}$} & \multicolumn{2}{|c|}{$120^{\circ} \cdot \mathrm{s}^{-1}$} & \multicolumn{2}{|c|}{$150^{\circ} \cdot \mathrm{s}^{-1}$} & \multicolumn{2}{|c|}{$180^{\circ} \cdot \mathrm{s}^{-1}$} & \multicolumn{2}{|c|}{$210^{\circ} \cdot \mathrm{s}^{-1}$} & \multicolumn{2}{|c|}{$240^{\circ} \cdot \mathrm{s}^{-1}$} & \multicolumn{2}{|c|}{$270^{\circ} \cdot \mathrm{s}^{-1}$} \\
\hline & $\begin{array}{c}\text { PT } \\
(\mathbf{N m})\end{array}$ & $\begin{array}{c}\text { APT } \\
\left({ }^{\circ}\right)\end{array}$ & $\begin{array}{c}\text { PT } \\
\text { (Nm) }\end{array}$ & $\begin{array}{c}\text { APT } \\
\left({ }^{\circ}\right)\end{array}$ & $\begin{array}{c}\begin{array}{c}\text { PT } \\
(\mathbf{N m})\end{array} \\
\end{array}$ & $\begin{array}{c}\text { APT } \\
\left({ }^{\circ}\right)\end{array}$ & $\begin{array}{c}\begin{array}{c}\text { PT } \\
(\mathbf{N m})\end{array} \\
\end{array}$ & $\begin{array}{c}\text { APT } \\
\left({ }^{\circ}\right)\end{array}$ & $\begin{array}{c}\begin{array}{c}\text { PT } \\
(\mathbf{N m})\end{array} \\
\end{array}$ & $\begin{array}{c}\text { APT } \\
\left({ }^{\circ}\right)\end{array}$ & $\begin{array}{c}\mathrm{PT} \\
(\mathrm{Nm})\end{array}$ & $\begin{array}{c}\text { APT } \\
\left({ }^{\circ}\right)\end{array}$ & $\begin{array}{c}\text { PT } \\
(\mathbf{N m})\end{array}$ & $\begin{array}{c}\text { APT } \\
\left({ }^{\circ}\right)\end{array}$ & $\begin{array}{c}\text { PT } \\
\text { (Nm) }\end{array}$ & $\begin{array}{c}\text { APT } \\
\left({ }^{\circ}\right)\end{array}$ \\
\hline Treatment effect uninvolved limb & 44.9 & -4 & 50.7 & -9 & 30.9 & 2 & 7.2 & 2 & 22.4 & -3 & 43.5 & -22 & 34.3 & -37 & 25.4 & -24 \\
\hline Treatment effect treatment limb & 70.3 & -22 & 49.3 & -14 & 51.4 & -14 & 52.6 & -35 & 58.9 & -17 & 36 & -14 & 36.2 & -41 & 21.5 & 3 \\
\hline Treatment effect uninvolved limb (\%) & 25 & & 27 & & 17 & & 4 & & 12 & & 24 & & 20 & & 14 & \\
\hline Treatment effect treatment limb (\%) & 38 & & 27 & & 28 & & 28 & & 32 & & 20 & & 20 & & 12 & \\
\hline SEM & 30.2 & 10 & 20.4 & 6 & 21 & 6 & 24.2 & 16 & 24.3 & 7 & 15.8 & 18 & 15.6 & 23 & 13.1 & 13 \\
\hline \multirow{3}{*}{ conKE } & \multicolumn{16}{|c|}{ Angular velocity } \\
\hline & \multicolumn{2}{|c|}{$60^{\circ} \cdot s^{-1}$} & \multicolumn{2}{|c|}{$90^{\circ} \cdot \mathrm{s}^{-1}$} & \multicolumn{2}{|c|}{$120^{\circ} \cdot \mathrm{s}^{-1}$} & \multicolumn{2}{|c|}{$150^{\circ} \cdot \mathrm{s}^{-1}$} & \multicolumn{2}{|c|}{$180^{\circ} \cdot \mathrm{s}^{-1}$} & \multicolumn{2}{|c|}{$210^{\circ} \cdot \mathrm{s}^{-1}$} & \multicolumn{2}{|c|}{$240^{\circ} \cdot \mathrm{s}^{-1}$} & \multicolumn{2}{|c|}{$270^{\circ} \cdot \mathbf{s}^{-1}$} \\
\hline & $\begin{array}{c}\text { PT } \\
(\mathbf{N m})\end{array}$ & $\begin{array}{c}\text { APT } \\
\left({ }^{\circ}\right)\end{array}$ & $\begin{array}{c}\text { PT } \\
(\mathbf{N m})\end{array}$ & $\begin{array}{c}\text { APT } \\
\left({ }^{\circ}\right)\end{array}$ & $\begin{array}{c}\begin{array}{c}\text { PT } \\
(\mathbf{N m})\end{array} \\
\end{array}$ & $\begin{array}{c}\text { APT } \\
\left({ }^{\circ}\right)\end{array}$ & $\begin{array}{c}\begin{array}{c}\text { PT } \\
(\mathbf{N m})\end{array} \\
\end{array}$ & $\begin{array}{l}\text { APT } \\
\left({ }^{\circ}\right)\end{array}$ & $\begin{array}{c}\text { PT } \\
(\mathbf{N m})\end{array}$ & $\begin{array}{c}\text { APT } \\
\left({ }^{\circ}\right)\end{array}$ & $\begin{array}{c}\text { PT } \\
(\mathbf{N m})\end{array}$ & $\begin{array}{c}\text { APT } \\
\left({ }^{\circ}\right)\end{array}$ & $\begin{array}{c}\text { PT } \\
(\mathbf{N m})\end{array}$ & $\begin{array}{c}\text { APT } \\
\left({ }^{\circ}\right)\end{array}$ & $\begin{array}{c}\text { PT } \\
(\mathbf{N m})\end{array}$ & $\begin{array}{c}\text { APT } \\
\left({ }^{\circ}\right)\end{array}$ \\
\hline Treatment effect uninvolved limb & -8.0 & -10 & -4.3 & -4 & 6.9 & -6 & 5.7 & -1 & 0.6 & -4 & 4.1 & -4 & 17.5 & -3 & 16.8 & -2 \\
\hline Treatment effect treatment limb & 53.4 & 3 & 48.2 & 7 & 35.8 & 4 & 55.3 & 3 & 44.7 & 2 & 48.5 & 11 & 47.6 & 0 & 46.4 & 16 \\
\hline Treatment effect uninvolved limb (\%) & -2 & & -3 & & -4 & & -1 & & -4 & & -4 & & -3 & & -2 & \\
\hline Treatment effect treatment limb (\%) & 29 & & 27 & & 22 & & 34 & & 29 & & 32 & & 32 & & 34 & \\
\hline SEM & 22 & 1 & 19.9 & 3 & 23.5 & 7 & 14.9 & 3 & 8.5 & 1 & 20.2 & 4 & 19.8 & 4 & 19.5 & 3 \\
\hline
\end{tabular}


Table 4. Angle specific and non-angle specific strength ratios recorded across all angular velocities at the point of return to play

\begin{tabular}{|c|c|c|c|c|c|c|c|c|c|}
\hline & & \multirow{2}{*}{\multicolumn{8}{|c|}{ Angular velocities }} \\
\hline & & & & & & & & & \\
\hline & & $60^{\circ} \cdot \mathbf{s}^{-1}$ & $90^{\circ} \cdot \mathbf{s}^{-1}$ & $120^{\circ} \cdot \mathrm{s}^{-1}$ & $150^{\circ} \cdot \mathrm{s}^{-1}$ & $180^{\circ} \cdot \mathbf{s}^{-1}$ & $210^{\circ} \cdot \mathbf{s}^{-1}$ & $240^{\circ} \cdot \mathrm{s}^{-1}$ & $270^{\circ} \cdot \mathbf{s}^{-1}$ \\
\hline & Uninvolved limb eccKF:conKE ratio & 0.80 & 0.90 & 0.90 & 0.98 & 1.00 & 1.00 & 0.97 & 1.13 \\
\hline Week & Uninvolved limb angle specific eccKF:conKE ratio & 1.89 & 1.26 & 1.55 & 1.45 & 1.61 & 1.27 & 1.20 & 1.37 \\
\hline \multirow[t]{2}{*}{24} & Treatment limb eccKF:conKE ratio & 1.00 & 1.04 & 1.15 & 1.13 & 1.00 & 1.19 & 1.19 & 1.28 \\
\hline & Treatment angle specific eccKF:conKE ratio & 1.88 & 1.97 & 1.68 & 1.40 & 1.38 & 2.07 & 1.93 & 1.75 \\
\hline
\end{tabular}




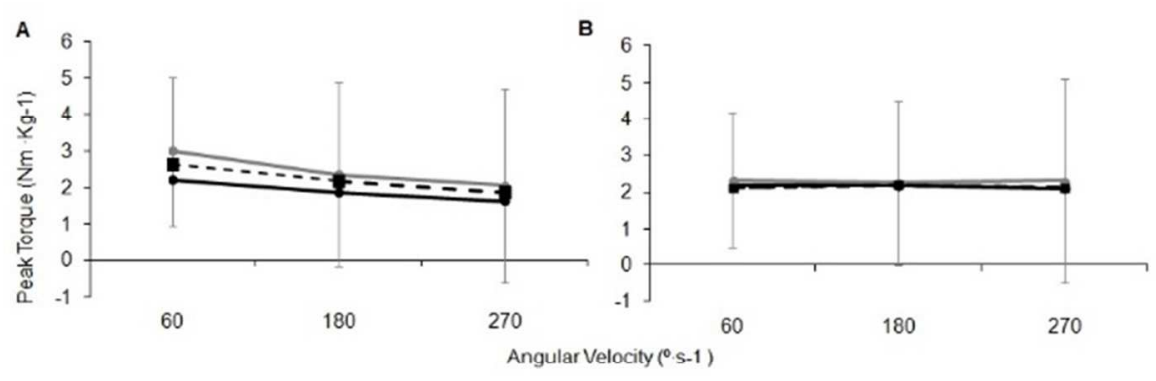

Figure 1. Isokinetic peak torque (normalized to body mass) of conKE (A) and eccKF (B) musculature recorded at 60,180 and $270^{\circ} \cdot \mathrm{s}-1$ for both the uninvolved limb ( ) and the treatment limb ( ) of the case, and also for the control group ( ) at the point of return to play.

$338 \times 190 \mathrm{~mm}(96 \times 96 \mathrm{DPI})$ 


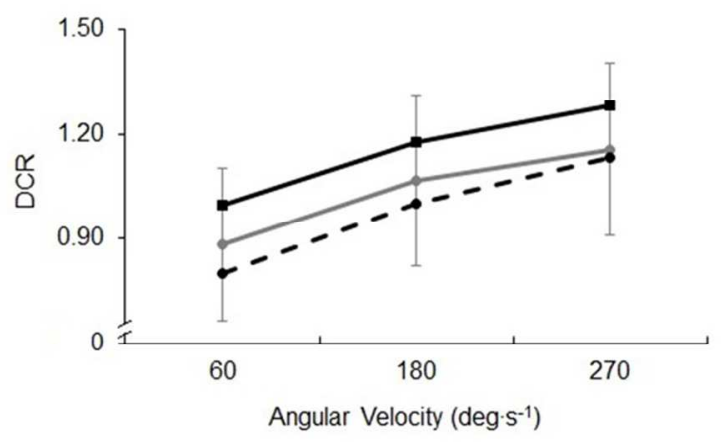

Figure 2. The eccKF:conKE strength ratio recorded at 60,180 and $270^{\circ} \cdot \mathrm{s}-1$ for uninvolved limb ( ), treatment limb ( ) of present case and control group ( ) at return to play.

$338 \times 190 \mathrm{~mm}(96 \times 96 \mathrm{DPI})$ 